\title{
A low volume 3D-printed temperature-controllable cuvette for UV visible spectroscopy
}

\author{
Jelena Pisaruka ${ }^{1}$, Marcus K. Dymond ${ }^{1 *}$
}

${ }^{1}$ Division of Chemistry, School of Pharmacy and Biological Sciences, University of Brighton, Huxley Building, Lewes Rd, Brighton, BN2 4GL, UK

* Author for correspondence: M.Dymond@brighton.ac.uk

\section{Abstract}

We report the fabrication of a 3D-printed water-heated cuvette that fits into a standard UV visible spectrophotometer. Full 3D-printable designs are provided and 3D-printing conditions have been optimised to provide options to print the cuvette in either acrylonitrile butadiene styrene or polylactic acid polymers, extending the range of solvents that are compatible with the design. We demonstrate the efficacy of the cuvette by determining the critical micelle concentration of sodium dodecyl sulphate at $40^{\circ} \mathrm{C}$, the molar extinction coefficients of cobalt nitrate and $d s$ DNA and by reproducing the thermochromic UV visible spectrum of a mixture of cobalt chloride, water and propan-2-ol. 
In recent years there has been a rapid expansion in the number and quality of commercially available, affordable, fused deposition modelling (FDM) 3D-printers. These FDM 3D-printers allow end users to design, test and construct bespoke 3D-fabricated plastic prototypes targeted to their own individual applications [1]. Researchers in the chemical and biomedical sciences have made bespoke integrated reactionware [2-7], DNA adhesives [8], inserts for cuvettes [9] or X-ray absorption spectroscopy [10] that enable spectroelectrochemistry to be performed, surgical models and synthetic organs [11] and microfluidic pumps [12]. However, whilst there are a significant number of recent research success stories demonstrating the potential applications of 3D-printers, a number of key challenges remain. In particular the additive manufacturing process of FDM printing has a tendency to create small gaps between successive extruded layers, meaning 3D-prints are not always air or watertight. This is a particular challenge for FDM 3D-printing in milli or microfluidic applications where the pressure in the device is increased. Strategies for solving this leakage problem differ, one approach is to construct devices with increased wall thicknesses, typically $4 \mathrm{~mm}$ [3], although this does impose a lower limit on the size of device that can be constructed. Alternatively, recent work [13] has shown that many of these printing imperfections in ABS prints can be removed with acetone and that 3D-prints treated in this way, post production, have potential uses in fluid handling on a variety of scales.

Here we report our recent success using FDM 3D-printing to develop an inexpensive water heated UV visible cuvette made from ABS or PLA, which fits into a standard UV visible spectrometer.

UV visible spectroscopy was performed on a dual beam Shimadzu Corporation UV-2410PC spectrometer equipped with a single monochromator. BRAND ${ }^{\circledR}$ disposable polystyrene cuvettes (Sigma-Aldrich UK) were used for control studies. Cobalt nitrate, sodium dodecyl sulphate (SDS) and dsDNA from salmon sperm were purchased from Sigma- Aldrich UK. Cobalt chloride was purchased from ACROS organics UK and acetone, propan-2-ol and methylene blue were purchased from Fisher Scientific UK. A REFCO (-1 to 3 Bar; class 1.6) pressure gauge and OMEGA ${ }^{\circledR}$ OM-EL-USB-TC thermocouple USB datalogger were used to measure pressure and temperature respectively. 3Dprinting was performed on a Makerbot Replicator 2X 3D printer (Makerbot Industries), $1.75 \mathrm{~mm}$ diameter ABS and PLA filaments were manufactured by Eliphilament and Makerbot Industries respectively. Prior to printing the build platform was covered with ScotchBlue ${ }^{\mathrm{TM}}$ adhesive tape for optimal adherence of the 3D-print. 3D-prints were designed in Autodesk123 and exported as STL files into Makerbot Desktop for slicing. The final optimised 3D printing settings for ABS and PLA are summarised in Tables S1 and S2 and fully printable designs are included as supporting information.

The UV visible spectrometer that we used was configured to accept standard $12 \times 12 \times 45 \mathrm{~mm}$ (width $x$ depth $x$ height) cuvettes; the incident beam centre was $15 \mathrm{~mm}$ from the bottom of the cuvette, and the $1 \mathrm{~mm}$ polystyrene walls leave a sample path length of $10 \mathrm{~mm}$. Therefore our water heated cuvette needed the following design criteria to function effectively.

1. Sample path length of $10 \mathrm{~mm}$

2. Sample centre $15 \mathrm{~mm}$ above the cuvette base.

3. Complete design no bigger than $12 \times 12 \mathrm{~mm}$ (width $\mathrm{x}$ depth) and around $45 \mathrm{~mm}$ in height

4. Watertight 
CAD designs of our 3D-printed water heated cuvette are shown in Figure 1A; we solved a number of problems before coming up with the final working cuvette. The most significant challenge encountered was leaking, either from the water-jacket chamber or the sample chamber. The origin of these leaks was two-fold, firstly small defects between layers resulting from the FDM printing process. Secondly, at printed vertices in the horizontal and vertical planes, sagging of the horizontal printed surface resulted in small voids, which leak. As noted, small defects can be fused using organic solvents [13], however bigger defects at vertices require carefully designed 3D-prints. A key design feature of our cuvette, which prevented sagging in the horizontal plane, was the inclusion of an inverted pyramid structure beneath the sample chamber, as noted in Figure 1B. The minimum and maximum sample volumes of the cuvette are 0.24 and $0.68 \mathrm{ml}$ respectively.

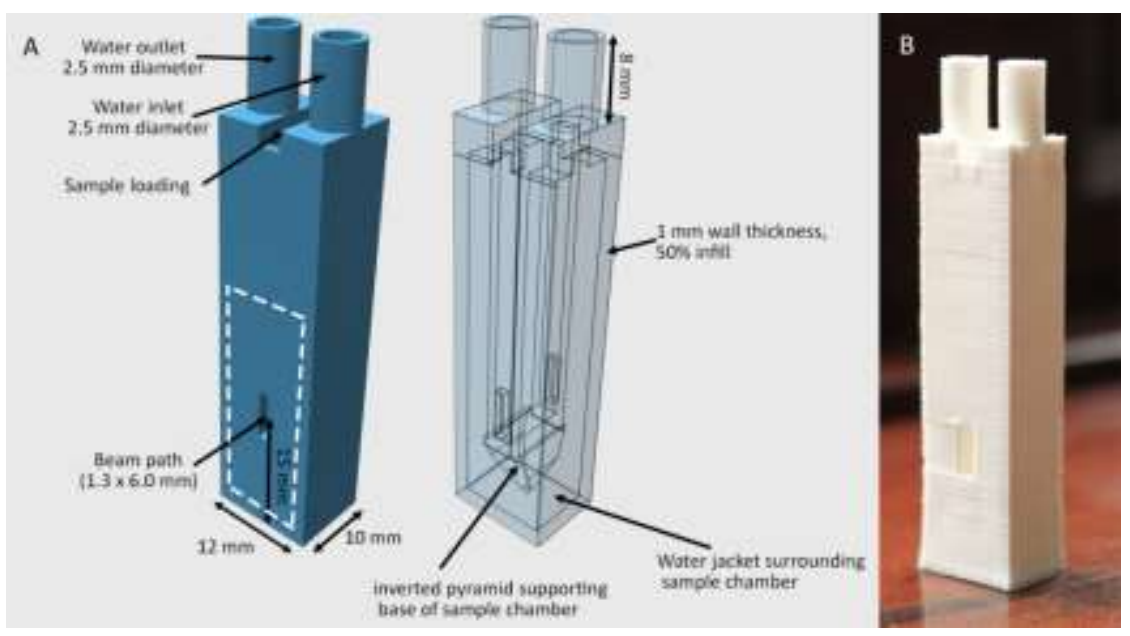

Figure 1A 3D-printed water heated cuvette, showing key dimensions and design features. The white dashed box indicates the approximate location of where optically transparent polystyrene, cut from polystyrene cuvettes was glued. Figure 1B shows a photograph of final cuvette printed in PLA.

Freshly printed $\mathrm{ABS}$ cuvettes were immersed in acetone (circa $20^{\circ} \mathrm{C}$ ) and freshly printed PLA cuvettes were immersed in chloroform ( $\operatorname{circa} 20^{\circ} \mathrm{C}$ ) for 8 seconds to fuse defects between the printed layers. Excess solvent was removed and the cuvettes were dried in a fume hood for 2 hours before optically transparent plastic, cut from disposable polystyrene cuvettes, was glued to the faces of the printed cuvette, Figure $1 \mathrm{~A}$. To make the sample chamber watertight a slurry of ABS in acetone or PLA in chloroform was used as the glue. This provides an optical quality plastic, which cannot be 3Dprinted. For studies utilising $d s$ DNA we extended the working wavelength range of the cuvette by gluing on quartz slides using Gorilla ${ }^{\mathrm{TM}}$ super glue adhesive. This particular product was chosen due to it retaining strength at $100^{\circ} \mathrm{C}$. After drying, cuvettes were pressure-tested to approximately $200 \mathrm{kPa}$ by connecting the water input to a plastic syringe and sealing the output. Only cuvettes that passed this pressure test were used in subsequent studies, where they were connected to a recirculating water bath and fitted into the UV visible spectrometer. It should be noted that 8 seconds immersion in organic solvent was optimal and less than 1 in 5 cuvettes failed the pressure test. However it is likely that ambient temperature and the initial resolution of the 3D print will affect success rates.

To ascertain how long samples would need to be equilibrated for during measurements, we characterised the heating rate of the cuvette. This was achieved by attaching the thermocouple 
probe the internal walls of the cuvette sample chamber. From an ambient water temperature of $17^{\circ} \mathrm{C}$ up to a maximum working temperature of $65^{\circ} \mathrm{C}$, the glass transition temperature of PLA, the water bath heated linearly at a rate of $0.033 \pm 0.001^{\circ} \mathrm{Cs}^{-1}$. Over the same temperature range the cuvette connected to the water bath heated linearly at $0.031 \pm 0.001^{\circ} \mathrm{Cs}^{-1}$ indicating no significant lag between the water bath and cuvette heating. As a precaution samples were left to equilibrate at a constant temperature for 5 minutes prior to measurement of their absorbance.

Using both disposable polystyrene cuvettes and our 3D-printed cuvette we determined the value of the molar extinction coefficient $(\varepsilon)$ for $\mathrm{Co}\left(\mathrm{NO}_{3}\right)_{2}$, at $510 \mathrm{~nm}$, to be $480 \pm 10 \mathrm{~m}^{2} \mathrm{~mol}^{-1}$ in water, indicating that the 3D-printed cuvette makes measurements as accurately as disposable plastic cuvettes. Figure S1A shows a plot of absorbance versus concentration for solutions of $\mathrm{Co}\left(\mathrm{NO}_{3}\right)_{2}$ determined in the 3D printed cuvette at room temperature.

As a further test we determined $\varepsilon$, at 260nm, of dsDNA from salmon sperm in the 3D-printed cuvette (with quartz covers glued to the sample chamber) at room temperature and compared it to the value we calculated using quartz cuvettes. Both sets of cuvettes gave molar extinction coefficients of dsDNA of $0.025 \pm 0.0005\left(\mu \mathrm{g} / \mathrm{ml}^{-1} \mathrm{~cm}^{-1}\right.$. The ratio of absorbance at 260 and $280\left(\mathrm{~A}_{260 / 280}\right)$, a measure of the protein contamination in DNA, was $1.81 \pm 0.01$ for both cuvette systems. Indicating that the 3D-printed cuvette with quartz covers also gives reproducible results when compared to the data obtained in quartz cuvettes. Figure S2A shows a plot of DNA absorbance at $260 \mathrm{~nm}$ versus concentration determined in the 3D-printed cuvette and Figure S2B shows the UV visible spectral plots of DNA from 200 to $400 \mathrm{~nm}$ at a range of concentrations obtained in the 3D-printed cuvette.

The next test we performed was to calculate the critical micelle concentration (CMC) of an amphiphile at an elevated temperature. We chose this test because phospholipids are amphiphiles and their critical aggregation concentration is important for biological processes, thus it is useful to measure this property at elevated temperature. However there are relatively few measurements of phospholipid $\mathrm{CMC}$ values in the literature and therefore for a more robust test we chose to determine the CMC of SDS, a commonly used anionic surfactant. The CMC of SDS has been determined many times in the literature using a number of different methods. In water at $25^{\circ} \mathrm{C}$ measurements of the CMC of SDS range from $8.3 \mathrm{mM}$ [14] using capillary electrophoresis, $8.3 \mathrm{mM}$ using a temperature shock method in combination with the dye acridine orange and UV visible spectroscopy, $8.1 \pm 0.12 \mathrm{mM}$ to $7.0 \mathrm{mM}$ [15] by conductance measurements [16] and titration calorimetry [17]. The CMC of SDS shows slight temperature dependence with literature values at $30^{\circ} \mathrm{C}$ in water of $7.3 \pm 0.3 \mathrm{mM}[18]$ and $7.2 \mathrm{mM}$ at $40^{\circ} \mathrm{C}$ and a general decrease in $\mathrm{CMC}$ with increasing temperature [19].

Using a UV visible method in combination with the dye methylene blue, such that the dye partitions into the interior of micelles changing the concentration of the dye in solution, we determined the $\mathrm{CMC}$ of $\mathrm{SDS}$ at $40^{\circ} \mathrm{C}$ to be $7.0 \pm 0.3 \mathrm{mM}$ in water, which agrees well with measurements in the literature. Figure S1B shows the results of this analysis, where the $\mathrm{CMC}$ is estimated from the graph by considering the gradients of two intersecting lines [20], which correspond to the linear increase in absorbance of the dye as a function of concentration in the presence and absence of micelles. There are a number of reports in the literature where the $\mathrm{CMC}$ of different amphiphiles, i.e. surfactants or phospholipid analogues, have been determined at $37^{\circ} \mathrm{C}$, which is particularly relevant for 
applications in biological systems [21]. We anticipate that this 3D-printed cuvette will be useful for these soft-matter applications.

As a final test we reproduced the thermochromic shift in the UV visible spectra of $\mathrm{CoCl}_{2}$ solutions of water and propan-2-ol, which arise due to the different absorbance spectra of cobalt chloride complexes in tetrahedral or octahedral geometries. In the tetrahedral arrangement these complexes are pink in colour and in the octahedral form these complexes are blue in colour. In solutions of water and propan-2-ol, a temperature-dependence exists whereby the tetrahedral form, stable at low temperature, exists in equilibrium with the octahedral form, favoured at higher temperature. This effect is driven by different solvation arrangements of water and propan-2-ol molecules being favoured at different temperatures and hence a different coordination structure for the cobalt chloride salt [22]. The percentage of water in the solvent mixture dictates the temperature range over which the thermochromic behaviour is observed, with higher water fractions shifting the dependence to higher temperatures [23].

We measured the thermochromic behaviour of $\mathrm{CoCl}_{2}$ solutions of water and propan-2-ol using our water heated cuvette and compared our spectra to those obtained by Dybko et al. [22] in a commercially available heated cuvette system. Figure 2 shows the temperature-dependence of the UV visible spectrum in the range of 400 to $800 \mathrm{~nm}$ for $10 \mathrm{ml}$ saturated $\mathrm{CoCl}_{2}$ in water added to $40 \mathrm{ml}$ propan-2-ol.
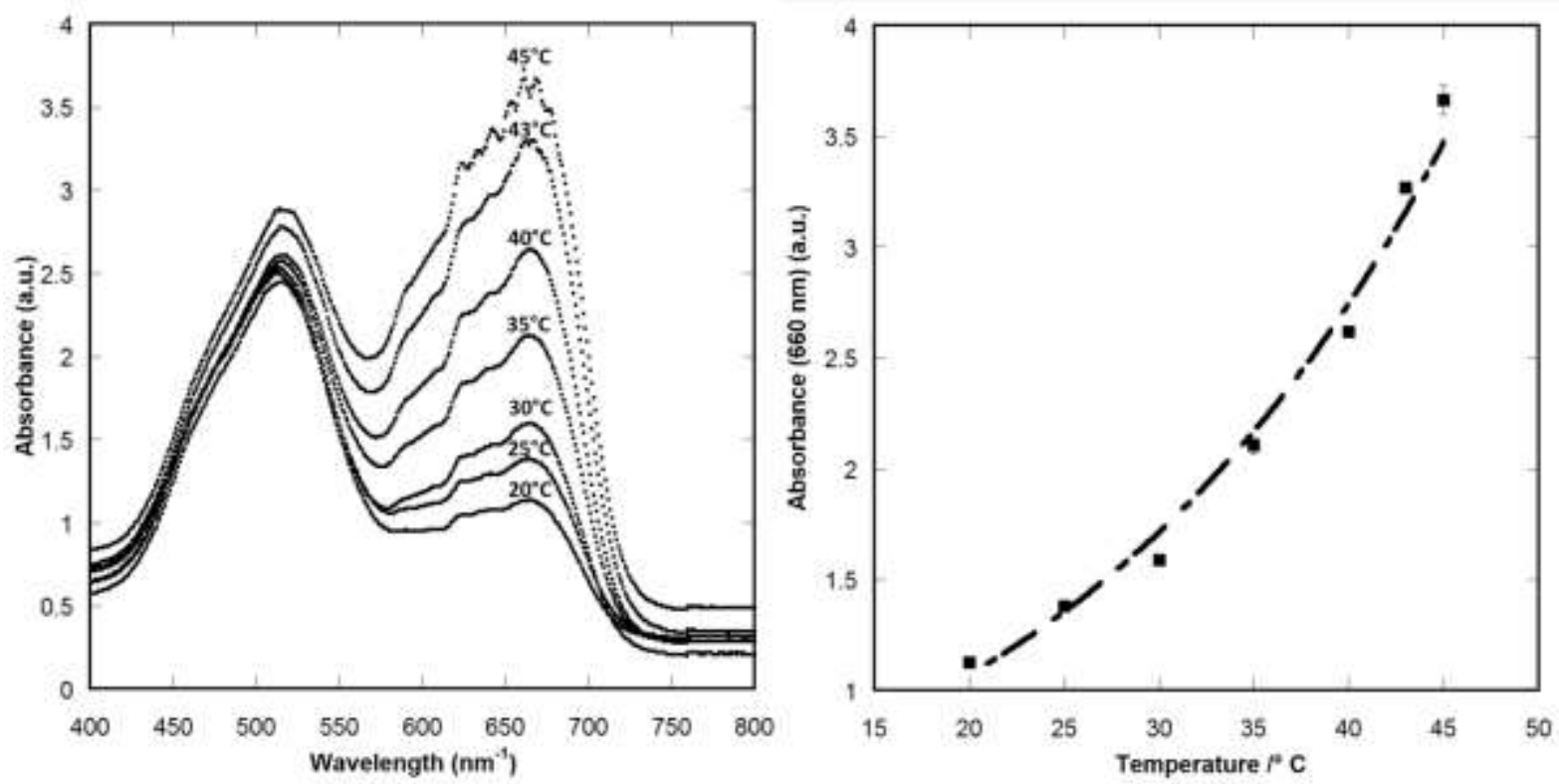

Figure 2A the thermochromic shift of UV visible spectra for $\mathrm{CoCl}_{2}$ in solutions of water and propan-2ol. Measurements were made at water bath temperatures of $20,25,30,35,40,43$ and $45^{\circ} \mathrm{C}$, the peak centred at $660 \mathrm{~nm}$ increases in size with temperature. Figure $2 \mathrm{~B}$ dependence of absorption at $660 \mathrm{~nm}$ on temperature for $\mathrm{CoCl}_{2}$ solutions in solutions of water and propan-2-ol. Absorbance data were extrapolated from Figure $2 \mathrm{~A}$ (at $660 \mathrm{~nm}$ ), the dashed line shows an exponential line of best fit over the temperature range studied $\left(y=0.42 \times \mathrm{e}^{(0.047 \times)}, \mathrm{R}^{2}=0.99\right)$. 
The results we obtain in Figure $2 \mathrm{~A}$ show identical trends to those reported in the literature [22], with one peak centred around $525 \mathrm{~nm}$ and the emergence of a second peak in the range of 600 to 700 $\mathrm{nm}$ with increasing temperature, corresponding to the octahedral cobalt complex. The maximum wavelength $\left(\lambda_{\max }\right)$ of absorbance of the octahedral complex is $660 \mathrm{~nm}$, which increases in absorbance intensity as the solution temperature is increased. The relationship between temperature and absorbance follows a sigmoidal dependence [22], rather than the linear dependence observed for concentration versus absorbance. Figure $2 \mathrm{~B}$ shows the temperature dependence of the absorbance at $660 \mathrm{~nm}$ determined in our 3D-printed cuvette also showing the trend reported by Dybko et al. [22].

We have 3D-printed and tested a water heated cuvette for UV visible spectroscopy, demonstrating that the 3D-printed cuvette provides reproducible temperature dependent spectra when compared to disposable cuvettes, quartz cuvettes and literature studies. We constructed our cuvette from both $A B S$ and PLA polymers making versions with 'windows' made from optically transparent polystyrene or quartz slides. The print reproducibility was greater for the cuvette constructed from PLA but the lower glass transition temperature of PLA $\left(\operatorname{circa} 65^{\circ} \mathrm{C}\right)$ means that PLA cuvettes have a lower working range when compared to cuvettes made $A B S$ (glass transition temperature circa $105^{\circ} \mathrm{C}$ ). PLA has different solvent compatibility [24] to ABS and is thus better suited for obtaining UV visible spectra in a range of organic solvents although both cuvettes can be used for water-based studies. The beam centre on our spectrophotometer was $15 \mathrm{~mm}$, whilst this is almost standard, our design can be modified for spectrometers with different beam centre heights. The material cost of producing the cuvette is around $f 0.10$ pounds sterling and subject to the constraints of dimension it is likely that these cuvettes are compatible with microelectrodes further extending the range of applications. In particular we foresee that this cuvette is ideal for preliminary research work, when conventional heated UV visible machines are not available, and for educational users.

\section{Acknowledgements}

The authors thank Lisa O'Rourke for proof-reading the document. This work was supported by the School of Pharmacy and Biological Sciences, University of Brighton who provided start-up funding for MKD to purchase the 3D-printer. 


\section{References}

[1] C. Schubert, M.C. van Langeveld, L.A. Donoso, Innovations in 3D printing: a 3D overview from optics to organs, Br. J. Ophthalmol. (2013) 159-161. doi:10.1136/bjophthalmol-2013-304446.

[2] P.J. Kitson, M.H. Rosnes, V. Sans, V. Dragone, L. Cronin, Configurable 3D-Printed millifluidic and microfluidic "lab on a chip" reactionware devices, Lab Chip. 12 (2012) 3267. doi:10.1039/c2lc40761b.

[3] P.J. Kitson, R.J. Marshall, D. Long, R.S. Forgan, L. Cronin, 3D Printed High-Throughput Hydrothermal Reactionware for Discovery, Optimization, and Scale-Up, Angew. Chemie Int. Ed. 53 (2014) 12723-12728.

[4] G. Chisholm, P.J. Kitson, N.D. Kirkaldy, L.G. Bloor, L. Cronin, 3D printed flow plates for the electrolysis of water: an economic and adaptable approach to device manufacture, Energy Environ. Sci. 7 (2014) 3026-3032. doi:10.1039/c4ee01426j.

[5] P.J. Kitson, M.D. Symes, V. Dragone, L. Cronin, Combining 3D printing and liquid handling to produce user-friendly reactionware for chemical synthesis and purification, Chem. Sci. 4 (2013) 3099-3103. doi:10.1039/c3sc51253c.

[6] J.S. Mathieson, M.H. Rosnes, V. Sans, P.J. Kitson, L. Cronin, Continuous parallel ESI-MS analysis of reactions carried out in a bespoke 3D printed device, Beilstein J. Nanotechnol. 4 (2013) 285-291. doi:10.3762/bjnano.4.31.

[7] V. Dragone, V. Sans, M.H. Rosnes, P.J. Kitson, L. Cronin, 3D-printed devices for continuousflow organic chemistry, Beilstein J. Org. Chem. 9 (2013) 951-959. doi:10.3762/bjoc.9.109.

[8] P.B. Allen, Z. Khaing, C.E. Schmidt, A.D. Ellington, 3D Printing with Nucleic Acid Adhesives, ACS Biomater. Sci. Eng. 1 (2015) 19-26.

[9] J.M. Brisendine, A.C. Mutter, J.F. Cerda, R.L. Koder, A three-dimensional printed cell for rapid, low-volume spectroelectrochemistry, Anal. Biochem. 439 (2013) 1-3.

doi:10.1016/j.ab.2013.03.036.

[10] E. Achilli, A. Minguzzi, A. Visibile, C. Locatelli, A. Vertova, A. Naldoni, S. Rondinini, F. Auricchio, S. Marconi, M. Fracchia, P. Ghigna, 3D-printed photo-spectroelectrochemical devices for in situ and in operando X-ray absorption spectroscopy investigation, J. Synchrotron Rad. 23 (2016) 622-628.

[11] S. V Murphy, A. Atala, 3D bioprinting of tissues and organs, Nat. Biotechnol. 32 (2014) 773785.

[12] D.J. Thomas, Z. Tehrani, B. Redfearn, 3-D printed composite microfluidic pump for wearable biomedical applications, Addit. Manuf. 9 (2016) 30-38. doi:10.1016/j.addma.2015.12.004.

[13] E.J. McCullough, V.K. Yadavalli, Surface modification of fused deposition modeling ABS to enable rapid prototyping of biomedical microdevices, J. Mater. Process. Technol. 213 (2013) 947-954. doi:10.1016/j.jmatprotec.2012.12.015.

[14] A. Cifuentes, J.L. Bernal, J.C. Diez-Masa, Determination of critical micelle concentration values using capillary electrophoresis instrumentation, Anal. Chem. 69 (1997) 4271-4274. doi:10.1021/ac970696n.

[15] A. Fernández-Alonso, C. Bravo-Díaz, Effects of micellar aggregates on the kinetics and 
mechanism of the reaction between 4-nitrobenzenediazonium ions and some amino acids, Helv. Chim. Acta. 90 (2007) 1141-1151. doi:10.1002/hlca.200790113.

[16] E. Fuguet, C. Ràfols, M. Rosés, E. Bosch, Critical micelle concentration of surfactants in aqueous buffered and unbuffered systems, Anal. Chim. Acta. 548 (2005) 95-100. doi:10.1016/j.aca.2005.05.069.

[17] M.J. Blandamer, B. Briggs, P.M. Cullis, K.D. Irlam, J.B.F.N. Engberts, J. Kevelam, Titration microcalorimetry of adsorption processes in aqueous systems Interaction of sodium dodecylsulfate and sodium decylsulfate with poly(N-vinylpyrrolidone), J. Chem. Soc. Faraday Trans. 94 (1998) 259-266. doi:10.1039/a704667g.

[18] W. Loh, L.A.C. Teixeira, L. Lee, Isothermal Calorimetric Investigation of the Interaction of Poly (N -isopropylacrylamide ) and lonic Surfactants, J. Phys. Chem. B. 108 (2004) 3196-3201. doi:10.1021/jp037190v.

[19] N.S. Babu, Thermodynamic study of polymersurfactant interaction in aqueous system, J. Indian Chem. Soc. 83 (2006) $39-41$.

[20] A. Domínguez, A. Fernández, N. González, E. Iglesias, L. Montenegro, Determination of Critical Micelle Concentration of Some Surfactants by Three Techniques, J. Chem. Educ. 74 (1997) 1227-1231. doi:10.1021/ed074p1227.

[21] M.K. Dymond, G.S. Attard, Cationic type I amphiphiles as modulators of membrane curvature elastic stress in vivo., Langmuir. 24 (2008) 11743-11751. doi:10.1021/la8017612.

[22] A. Dybko, W. Wróblewski, E. Roźniecka, J. Maciejewski, Z. Brzózka, Comparison of two thermochromic solutions for fibre optic temperature probes, Sensors Actuators, A Phys. 76 (1999) 203-207. doi:10.1016/S0924-4247(99)00030-8.

[23] K. Sone, Y. Fukuda, J. Mizusaki, K. Moriyama, Bemerkungen über Thermochromie von Kobalt (II) chloridlösungen in organischen Medien, 1. Mitt.: Lösungen in verschiedenen Alkoholen., Monatshefte Für Chemie/Chemical Mon. 107 (1976) 271-281.

[24] S. Abbot, Chemical Compatibility of Poly(Lactic Acid): A Practical Framework Using Hansen Solubility Parameters, in: Poly(Lactic Acid) Synth. Struct. Prop. Process. Appl., John Wiley \& Sons, Inc., Hoboken, NJ., 2010: pp. 83-95. doi:10.1002/9780470649848. 
Supporting Information: A low volume 3D-printed temperature-controllable cuvette for UV Visible spectroscopy

Jelena Pisaruka ${ }^{1}$, Marcus K. Dymond ${ }^{1 *}$

${ }^{1}$ Division of Chemistry, School of Pharmacy and Biological Sciences, University of Brighton, Huxley Building, Lewes Rd, Brighton, BN2 4GL, UK

* Author for correspondence: M.Dymond@brighton.ac.uk 


\section{Supplementary methodology}

\section{D-printing conditions}

During construction we trialled different infill densities before settling on a density of $50 \%$ for the final design, at lower infill densities (10\%) we found the cuvette was fragile and distorted more easily during prolonged heating. Aside from danger of leakage, this distortion caused experimental artefacts when measuring the absorbance spectra of samples. At higher infill density, close to $100 \%$, 3D-prints were stronger but distorted more during printing. In part this distortion was due to the extruded filament not cooling sufficiently before the next layer was added, thus as the printer extruder extrudes the current layer, layers below are slightly mobile. This problem can be eliminated by increasing the minimum layer duration, see Tables S1 and S2, in the print settings and tends to be related to the size of the structure being printed. It was particularly problematic when printing the small $2.5 \mathrm{~mm}$ diameter water inlet and water outlet. Our highest quality cuvettes were obtained by 3D-printing a monolith beside the cuvette, which gave each layer sufficient time to cool before the next was added. This approach also prevented the build-up of molten plastic on the extruder head which can result from extending the minimum layer duration.

Table S1. Optimal print settings for ABS cuvettes on the MakerBot Replicator 2X.

\begin{tabular}{|cccc|}
\hline Extruder Temperature & $245^{\circ} \mathrm{C}$ & Platform Temperature & $110^{\circ} \mathrm{C}$ \\
Travel Speed & $150 \mathrm{~mm} / \mathrm{s}$ & Z-axis Travel Speed & $23 \mathrm{~mm} / \mathrm{s}$ \\
Minimum Layer Duration & $5.0 \mathrm{~s}$ & First Layer Raft Print Speed & $50 \mathrm{~mm} / \mathrm{s}$ \\
Infill Print Speed & $90 \mathrm{~mm} / \mathrm{s}$ & Inserts Print Speed & $90 \mathrm{~mm} / \mathrm{s}$ \\
Outlines Print Speed & $40 \mathrm{~mm} / \mathrm{s}$ & Raft Print Speed & $90 \mathrm{~mm} / \mathrm{s}$ \\
Raft Base Print Speed & $10 \mathrm{~mm} / \mathrm{s}$ & Bridges Print Speed & $40 \mathrm{~mm} / \mathrm{s}$ \\
First Layer Print Speed & $30 \mathrm{~mm} / \mathrm{s}$ & Infill Density & $50 \%$ \\
Infill Pattern & Hexagonal & Layer Height & $0.20 \mathrm{~mm}$ \\
Infill Layer Height & $0.20 \mathrm{~mm}$ & Number of Shells & 2 \\
Roof Thickness & $0.80 \mathrm{~mm}$ & Floor Thickness & $0.80 \mathrm{~mm}$ \\
Coarseness & $0.0001 \mathrm{~mm}$ & Raft-Model Spacing & $0.35 \mathrm{~mm}$ \\
Raft Margin & $4.0 \mathrm{~mm}$ & Support & Off \\
Bridging & $\mathrm{Off}$ & Filament Diameter & $1.77 \mathrm{~mm}$ \\
Retraction Distance & $1.3 \mathrm{~mm}$ & Retraction Speed & $25 \mathrm{~mm} / \mathrm{s}$ \\
Restart Speed & $25 \mathrm{~mm} / \mathrm{s}$ & Extra Restart Distance & $0.0 \mathrm{~mm}$ \\
& & & \\
\hline
\end{tabular}

Table S2. Optimal print settings for PLA cuvettes on the MakerBot Replicator 2X. 


\begin{tabular}{|cccc|}
\hline Extruder Temperature & $220^{\circ} \mathrm{C}$ & Platform Temperature & $110^{\circ} \mathrm{C}$ \\
Travel Speed & $150 \mathrm{~mm} / \mathrm{s}$ & Z-axis Travel Speed & $23 \mathrm{~mm} / \mathrm{s}$ \\
Minimum Layer Duration & $5.0 \mathrm{~s}$ & First Layer Raft Print Speed & $50 \mathrm{~mm} / \mathrm{s}$ \\
Infill Print Speed & $90 \mathrm{~mm} / \mathrm{s}$ & Inserts Print Speed & $90 \mathrm{~mm} / \mathrm{s}$ \\
Outlines Print Speed & $40 \mathrm{~mm} / \mathrm{s}$ & Raft Print Speed & $90 \mathrm{~mm} / \mathrm{s}$ \\
Raft Base Print Speed & $10 \mathrm{~mm} / \mathrm{s}$ & Bridges Print Speed & $40 \mathrm{~mm} / \mathrm{s}$ \\
First Layer Print Speed & $30 \mathrm{~mm} / \mathrm{s}$ & Infill Density & $50 \%$ \\
Infill Pattern & Hexagonal & Layer Height & $0.20 \mathrm{~mm}$ \\
Infill Layer Height & $0.20 \mathrm{~mm}$ & Number of Shells & 2 \\
Roof Thickness & $0.80 \mathrm{~mm}$ & Floor Thickness & $0.80 \mathrm{~mm}$ \\
Coarseness & $0.0001 \mathrm{~mm}$ & Raft-Model Spacing & $0.35 \mathrm{~mm}$ \\
Raft Margin & $4.0 \mathrm{~mm}$ & Support & $\mathrm{Off}$ \\
Bridging & Off & Filament Diameter & $1.77 \mathrm{~mm}$ \\
Retraction Distance & $1.3 \mathrm{~mm}$ & Retraction Speed & $25 \mathrm{~mm} / \mathrm{s}$ \\
Restart Speed & $25 \mathrm{~mm} / \mathrm{s}$ & Extra Restart Distance & $0.0 \mathrm{~mm}$ \\
\hline
\end{tabular}

\section{Characterisation of the thermal sensitivity of the 3D-printed cuvette}

The thermal sensitivity of the 3D-printed cuvette was determined to ensure that in experimental runs sufficient time would be left for samples to reach thermodynamic equilibrium. The heating rates of both the water bath and the 3D-printed cuvette were determined using a digital thermocouple, measuring the temperature at 30 second intervals.

Determination of the molar extinction coefficient of $\mathrm{Co}\left(\mathrm{NO}_{3}\right)_{2}$ in water

$\mathrm{Co}\left(\mathrm{NO}_{3}\right)_{2}$ solutions were prepared with concentrations of $0.025 \mathrm{M}, 0.04 \mathrm{M}, 0.05 \mathrm{M}, 0.08 \mathrm{M}, 0.10 \mathrm{M}$, $0.133 \mathrm{M}$ and $0.20 \mathrm{M}$ and their absorbance measured over the range $350-650 \mathrm{~nm}$ using water as a blank. Each concentration was measured in triplicate using disposable cuvettes or a water heatedprinted cuvettes made from ABS and PLA and background subtracted using the appropriate cuvette containing water. The molar extinction coefficient $(\varepsilon)$ was determined using the Beer-Lambert principle from linear fits to plots of the $\mathrm{Co}\left(\mathrm{NO}_{3}\right)_{2}$ concentration versus their absorbance at $510 \mathrm{~nm}$, which yields $\varepsilon_{510}$ as the function of the gradient of the line and the path length $(10 \mathrm{~mm})$, see Equation 1.

$$
A=\varepsilon c l \quad \text { Equation 1, }
$$

\section{Determination of the molar extinction coefficient of dsDNA in $50 \mathrm{mM}$ Trizma buffer $\mathrm{pH} 7.4$}

In $50 \mathrm{mM}$ Trizma buffer, dsDNA solutions were prepared with concentrations of 12.6, 23.9, 34.1, $43.3,51.6 \mu \mathrm{g} \mathrm{ml}^{-1}$ and their absorbance measured over the range $200-400 \mathrm{~nm}$ using $50 \mathrm{mM}$ Trizma 
buffer as a blank. Each concentration was measured in triplicate using quartz cuvettes or a water heated-printed cuvettes fitted with quartz covers made from ABS. The molar extinction coefficient $(\varepsilon)$ was determined using the Beer-Lambert principle from linear fits to plots of the dsDNA concentration versus their absorbance at $260 \mathrm{~nm}$, which yields $\varepsilon_{260}$ as the function of the gradient of the line and the path length $(10 \mathrm{~mm})$, see Equation 1.

\section{Determination of the CMC of $S D S$ at $40^{\circ} \mathrm{C}$}

Ten solutions of SDS were prepared at $3 \mathrm{mM}, 4 \mathrm{mM}, 5 \mathrm{mM}, 6 \mathrm{mM}, 7 \mathrm{mM}, 8 \mathrm{mM}, 9 \mathrm{mM}, 10 \mathrm{mM}, 11$ $\mathrm{mM}$ and $12 \mathrm{mM}$ in water, containing $10^{-5} \mathrm{M}$ methylene blue. The water heated cuvette was placed into the UV visible spectrometer and heated to $40^{\circ} \mathrm{C}$ before the background absorbance of $10^{-5} \mathrm{M}$ methylene blue in water was recorded. Absorbance measurements were made in triplicate between 650 and $670 \mathrm{~nm}$ and in increasing SDS concentrations, allowing 5 minutes for samples to reach thermal equilibrium. Samples were removed from the cuvette using a glass pipette before rinsing with $10^{-5} \mathrm{M}$ methylene blue in water, prior to the addition of the next sample. The CMC was determined using absorbance measurements at $660 \mathrm{~nm}$.

Determination of the thermochromic shift of mixtures of $\mathrm{CoCl}_{2}$, water and propan-2-ol

$10 \mathrm{ml}$ of saturated aqueous $\mathrm{CoCl}_{2}$ was added to $40 \mathrm{~mL}$ of isopropyl alcohol as previously published [1]. The 3D-printed cuvette was connected to a water bath placed into the UV visible machine and mixture absorbance between $400-800 \mathrm{~nm}$ was measured at temperatures between $15^{\circ} \mathrm{C}-45^{\circ} \mathrm{C}$ in increments, leaving 5 minutes for thermal equilibration between measurements.

\section{Supplementary Figures}



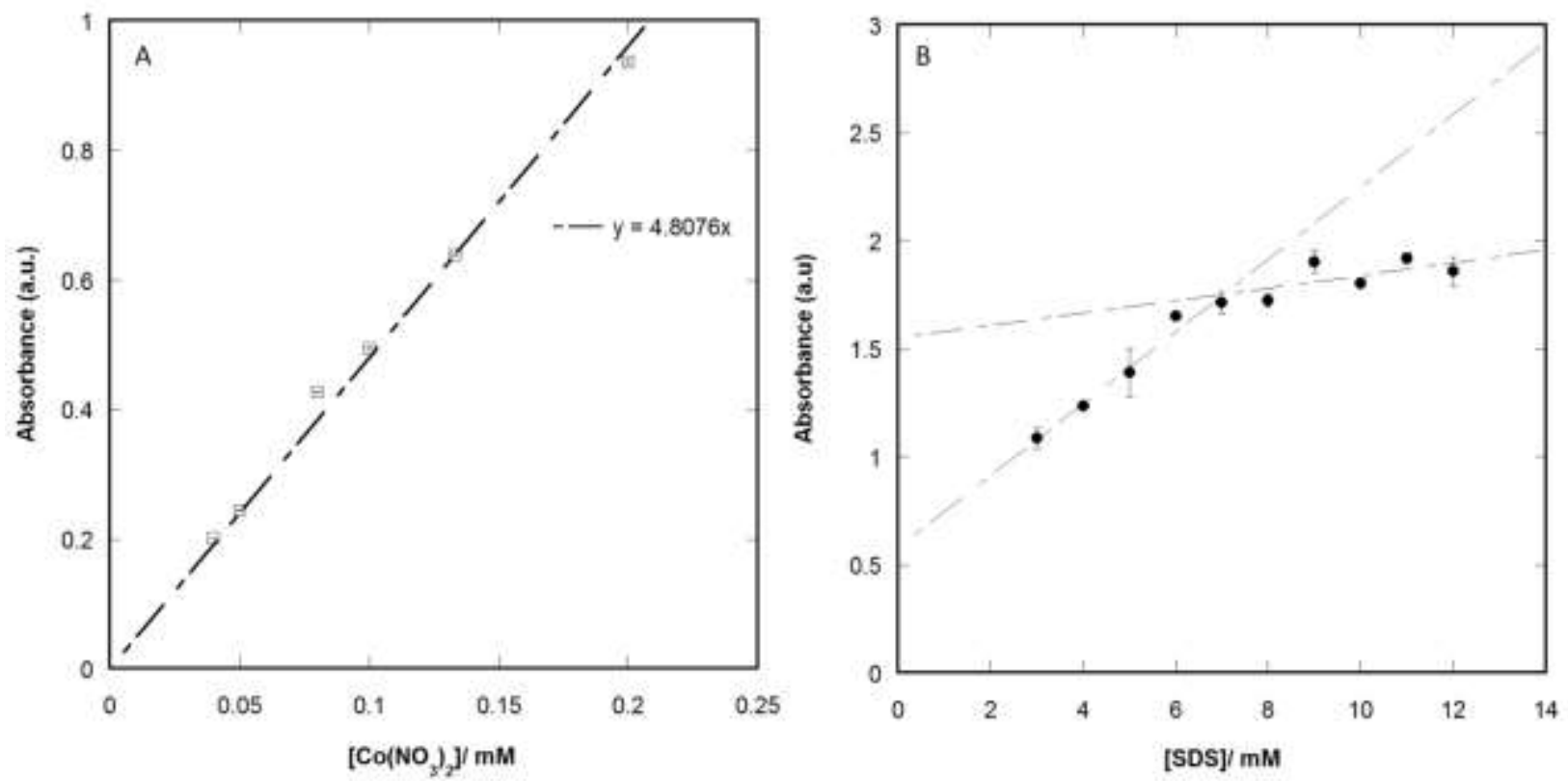

Figure $\mathrm{S} 1 \mathrm{~A}$, the molar extinction coefficient determined for $\mathrm{Co}\left(\mathrm{NO}_{3}\right)_{2}$ at $510 \mathrm{~nm}$ and Figure $\mathrm{S} 1 \mathrm{~B}$ the $\mathrm{CMC}$ of SDS determined at $40^{\circ} \mathrm{C}$ using the low-volume 3D-printed cuvette. The $\mathrm{CMC}$ is determined from Figure S1B as the point where the two lines intersect.
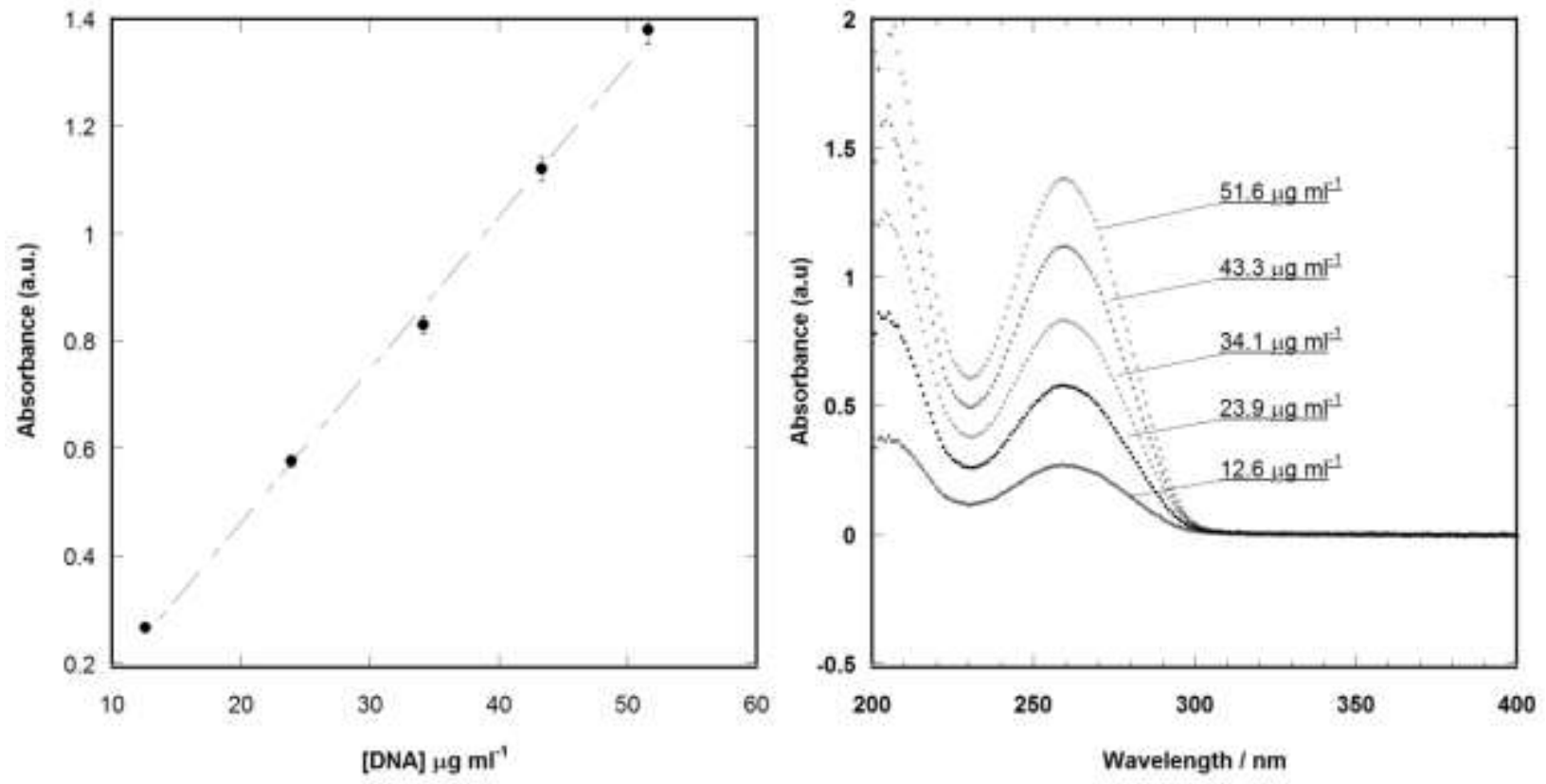

Figure S2A the molar extinction coefficient determined for $d s D N A$ at $510 \mathrm{~nm}$ and Figure S2B, the absorbance spectrum of $d s$ DNA from 200 to $400 \mathrm{~nm}$ at a range of concentrations. Spectra in both figures were obtained using the 3D-printed cuvette fitted with quartz covers.

[1] A. Dybko, W. Wróblewski, E. Roźniecka, J. Maciejewski, Z. Brzózka, Comparison of two thermochromic solutions for fibre optic temperature probes, Sensors Actuators, A Phys. 76 
(1999) 203-207. doi:10.1016/S0924-4247(99)00030-8. 